\title{
The Effectiveness of Citizen Participation in Public Hearing of Current China
}

\author{
Gao Fufeng \\ North China Electric Power University, Beijing, China
}

\begin{abstract}
Public hearing system is regarded as the soul and core of modern administrative procedure; it plays a more and more important part in modern administrative affairs. Public hearing is an important way to listen to the voice of the public, and the main method to gauge public opinion before making public policies, laws, and regulations. In recent years, with the growing awareness of civic participation, public hearing system has played a big role in public policy-making process in contemporary China, but there is also a phenomenon that citizen participation is largely symbolic in most of the hearing, citizen participation cannot play its due role, and the effectiveness of citizen participation in public hearing is limited. Based on this background, the analyses about how to strengthen public hearing system construction, improve the representativeness of the representative and information disclosure system, are all very important to improve the validity of citizen participation in public hearings now to China.
\end{abstract}

Keywords: public hearing, public hearing system, citizen participation

The major decisions and draft legislation of government authorities should listen to the voice of the public had institutionalized in the file of State Council of China since 2004. After that, some important administrative regulatory documents like "Rules and Procedures Regulations", "Administrative Rulemaking Procedures Regulations", and "Work Rules of the State Council", reiterated the important role of administrative hearing system. So the administrative hearing system has been gradually gone into public life.

\section{The Status of Citizen Participation in Public Hearings}

When the public interest or multi-stakeholder coordination and adjusted in the process of public administration, administrative organs will hold the meeting to listen to public opinion in the form of a program as public hearings. It includes the administrative rulemaking process, legislative hearings, involving multi-stakeholder licensing hearings and administrative hearings which involve complex problems, etc.

Although public hearings have been greatly developed in our country for about 10 years, the general public participation in most of hearing process, but the effectiveness of citizen participation had compromised in practice, which reflected in the following.

\section{The Representatives Are not on Behalf of the Public}

Some local governments have attached great importance to social organizations and public participation in the public hearing in recent practice of public hearings, however, there is no statutory procedure to elect the

Corresponding author: Gao Fufeng, LL.M., associate professor, Humanities and Social Sciences School, North China Electric Power University; research fields: public policy analysis and government functions. E-mail: tiechgao@sina.com. 
representatives, most of the representatives who will participate the public hearing are selected by the administrative organization, so the public who has not have the same opinion as the administrative organization are all excluded. Maybe sometimes the public who has the different opinion are including, but they have no opportunity to speak or their speeches were ignored. Because there is no system to protect the representatives elected, most of the public hearings become formality. Even some "appointed representatives" and "confused representatives" are emerged in the public hearing meeting, they are on the behalf of organizers instead of the public, this kind of public hearing meeting has seriously affected the active participation of citizens. For example, before the residential water prices public hearing of Lanzhou city, most residents oppose domestic water prices raise during the consumer representatives' survey, but at the meeting site, there are only two against the price increases among 14 representatives.

\section{Public Hearing Opaque}

Public hearing opaque, lack of "public", the name under the guise of confidentiality, in fact, manipulating the hearing results.

Most of public hearings are opaque, and lack of "public". The organizers in order to manipulate the results of the hearing, many meetings are hold under the name of confidentiality. For example, before the educational "one fee" charges hearings had hold in Jiangsu Province Price Bureau, the content of the hearing was "strictly confidential", the materials which submitted to the hearing participants were also used as "confidential". The materials in most of the public hearings which provide to the representatives are marked "confidential note, after reading recover", and prohibit the representatives disclosing the information about the hearing meeting.

\section{Chairperson of the Hearing System Is Imperfect}

Hearing procedure is stated clearly by the "Administrative Punishment Law": Presiding officer of the hearing should be designated by the executive, who has no relation with the case, but clause is not specific. Moderators lack of independence and impartiality cause their benefits associated with the administrative executive (Sui, 2010).

\section{Hearing Result Is not Associated With the Policy Formulation}

In accordance with the "Price Law", price hearings are the duties of government price departments; they hold the price hearing is to know "the advice of consumers, operators, and interested parties", to demonstrate the necessity and feasibility of price adjustment programs, utility prices hearing does not have the final decision-making authority, the final decision belongs to the government guidance price departments at all levels of government. The result of the prices hearing just is a policy reference, the result reflected in the policy does not depend entirely on the policy makers, this makes the effectiveness of citizen participation uncertain.

\section{The Root Cause of the Low Effectiveness}

\section{The Administrative Departments Lack Awareness of Service}

In the public hearing process, the executive branch is the organizer of the public hearing, the purpose of the public hearing is to collect public opinions and suggestions. However, due to lack of awareness of service, public hearings will inevitably become into administrative departments to achieve their own interests "justification". In practice, public hearings involve multiple interests, the administration is not first placing to serve the people, "rent-seeking" phenomenon also occurs. 


\section{Public Hearing System Is Deficiencies}

Public hearings' institutional flaws are the main reason for why the effectiveness of citizen participation is not high. Effective participation of citizens is based on public hearings effectively, but for multi reasons that public hearings do not fully play its due role. Public hearings also due to some deficiencies in the system of law which led to omissions, but these defects are mainly found in the system itself, and therefore attributed to deficiencies in the system.

\section{Hearing Participants Selection Mechanism Is Unreasonable}

Hearing participants directly determine the effectiveness of citizen participation, who are the subject of a hearing in the hearing of citizen participation. The rough of the system design brings a lot of problems, leading to the selection of the hearing participants very irregular and arbitrary. Hearing organizers control participants of the hearing, the election of hearing participants is not open and the breadth of the hearing participants is inadequate.

As "Government Set Prices Hearings" provision, the method of administrative hearing participants generating is, one stakeholder voluntary enrollment, then generated by the organizers randomly; second, commissioned by the organizers of the mass society organizations, industry organizations, government departments recommended; third, experts, academics, government departments, social organizations, and other personnel are hired by the organizers (Su, 2010). In "Government Set Prices Hearings", the choice of the hearing participants referred to as "government price departments to hire hearing participants", since the choice of the representative referred to as "hire", then "employed" the hearing participants are more inclined to cooperate with managers, not easy to make different sounds. So the selection of hearing participants is randomly, it is inevitable that there will be cases of hearing participants controlled by the organizers.

\section{Hearing Participants Information Asymmetry}

In hearing process, symmetric information can be equally right to speak for hearing participants. The organizer should provide comprehensive, truthful information to the public accordance with national laws and regulations, enable them to combine their personal experience as well as summary information of the public who is represented to make a scientific and objective evaluation. For some public hearing organizers, they just open part of the information before public hearing, not even announce public hearings' materials and public hearing participants name list. In the hearing process, public hearing participants are absent of the right to speak, because the information of internal business and technical aspects have not been completely mastered by them. Of course, on the basis of the lack of comprehensive, real information, it is difficult for the public hearing participants to make a scientific and objective judgment.

\section{Lack of Supervision and Questions}

Under unopened public hearings and unjust situation, lack of supervision will greatly reduce the effectiveness of citizen participation. As for price hearing, hearing conclusion is hearing participants agree, partly agree, or disagree with the determination of transfer pricing schemes after they analyze the necessity and feasibility of price adjustment. Article 24 of the "Government Approach to Pricing Decisions" is "seven days after the hearing, the government price departments shall prepare the minutes of the hearing, and send them to representatives to sign. The hearing meeting opinion should be considered in price decision-making".

Correspondingly, the "Government Pricing Decisions Hearings Measures" Article 26 is "The government 
price departments shall announce the final results of pricing to the public". But for the "final outcome" and the decision-making process should be disclosure to public or does not stipulate. Otherwise, there is no much difference to hold a hearing or not, if only announced the final results without oversight and transparency, hearing docket has limited role for price decision-making organs (Bao, 2008).

\section{Ability of Hearing Participants Is Limited}

While hearing matters of public hearing have closed relationship to people's lives, but some hearing matters are highly specialized, if ordinary people participate in the hearing, even they can express their views in the public hearing, they cannot effectively participate because lack of knowledge and technique, and it may not be able to resolve hearing matters. Blindly emphasis on participation would not improve the effectiveness of citizen participation, effective participation is more dependent on the improvement of the participation. Such as Yuanmingyuan hearing which had been hold in Beijing, the hearing participants had intense discussions on one of the main topics: "Impermeable membrane would have what impact on surrounding ecological environment". In fact, this topic is a highly professional issue, ordinary people know a little about it, so the hearing meeting become a debate among technical experts which did not play a role in solving the problem.

\section{Improve the Effectiveness of Citizen Participation in Public Hearings}

If we want to make public policy reflect public opinion fully, improve the effectiveness of citizen participation in public hearings, we should do the following aspects:

\section{Improve the System Construction}

Based on the experience of practice of public hearing which had accumulated over the year, and combined with the opinions of experts and the public to improve the existing public hearing system to ensure truly play the role of public hearings in public decision-making. It should be institutionalized to the program, representative selection, and information public of public hearing, and oversight and audit by specialized agencies for implementation of the system.

\section{Ensure the Representativeness of Hearing Participants}

Real emphasis on the participation of representatives, who are selected by public in the course of the public hearing, hearing participants who participate the hearing should cover the one which has positive evaluation and negative perceptions. Hearing participants should follow the appropriate institutionalized electoral process and open democratic elections.

\section{Establish Appropriate Information Collection and Disclosure Mechanism}

Public hearing itself is an information activity, the transparency and information disclosure of public hearing process can improve public decision-making mechanism. In order to eliminate asymmetric information during public hearings, on one hand, we should improve the information disclosure mechanism, all hearings materials must open and transparent besides confidential information states by state law, such as time and place of the public hearing, the name list of public hearings participants, the hearing issues and relevant information, informed public hearings participants details of the hearings in advance, etc. On the other hand, improving the information disclosure system in accordance with the laws, society organizations, and the public has the right to inquire all the information, except confidentiality information in accordance with the relevant laws and regulations, and the agencies and members who are inquired must respond on time in accordance with the relevant systems and procedures, and also responsible for the truthfulness and completeness of the information disclosed by them. 


\section{Build Hearing Response Procedures}

The main concern of hearing response procedures is the result of the hearing which has or has not effected the final policy making-decision, and impact to what extent. Response program can perform by recording legal effect, and also achieve by hearing organizer announce the results of the hearing to the public and public policy programs, improve the effective and impartial of public hearing.

\section{Innovative Methods of Public Hearings}

Public hearings may take the form of on-site hearing, and can also be used as the way of network. Nowadays, the internet plays an important role in people's lives, more and more people began to express their views on the network, and even state leaders had interacted with users on the network. The vehicular traffic charges hearing which had hold in Wuhan, about the roads, bridges, and tunnels were built by loan, in addition, there had a web-site hearings, it had ensured the breadth of citizen participation in public hearing.

Above all, if we want to ensure the effective participation of citizens in public hearings, we should improve hearing system itself, increase the ability of citizens to participate in the initiative and civic participation, and promote citizen participation effectiveness, and enhancing administrative reform should be expedited as a precondition. Only we had improved in all aspects as above, the effectiveness of citizen participation in public hearings can complete, and the value of a public hearing can truly be achieved.

\section{References}

Bao, J. (2008). Research on the hearing system of utility prices. Jiangsu, China: Suzhou University.

Chen, Q. Y. (2011). Path of improving the system of public hearings. Sichuan, China: Sichuan Social Sciences.

Ding, W., \& Zhao, X. T. (2010). On the perfection of our citizens to participate in the hearing system. Theory Research, 7, 125.

Liu, Y. (2011). Perfect the hearing system to promote citizen participation in public policy formulation. Journal of Graduate School of Chinese Academy of Social Sciences, 1, 24.

Qing, Q. C. (2011). The establishment and perfection of China's administrative public hearing representative system. Jianghuai Tribune, 4, 120-121.

$\mathrm{Su}$, J. B. (2010). Decision of the hearing system. Liaoning, China: Jilin University.

Sui, Y. P. (2010). China's administrative hearing system. Journal of Qinghai Nationalities University, 36(4), 123.

Xu, Y. Q. (2011). The effectiveness of citizen participation in price hearing in China. Manager's Journal, 22, 82. 